\title{
Becker Value of Manila Rope by Photoelectric Reflectometry
}

\author{
Sanford B. Newman, Harry K. Hammond, III, and Helen F. Riddell
}

\begin{abstract}
Becker value, or reflectance under specified conditions, has been used for more than 20 years as an index of fiber quality in the purchase of manila cordage. The accepted method for determining Becker value requires a visual reflectometer. Previous attempts to use photoelectric reflectometers were unsuccessful because the instruments lacked sensitivity, attributable in part to the low transmittance of the chosen filter combination. Properly selected filters used with a sensitive reflectometer permit photoelectric determinations to be made with greater speed and precision than visual determinations. The results obtained photoelectrically agree well with the averages of visual determinations.
\end{abstract}

\section{Introduction}

Manila fiber (abacá) is one of the important raw materials or cordage. Rope made from this fiber was consumed at an annual rate of over 50,000 tons in $1939^{1}[1] .^{2}$ The Federal specification for manila rope [2] contains requirements for strength, weight, and other physical characteristics. Opinion in the industry, however, holds that serviceability is related to color, the dark grades of fiber being less serviceable than the lighter [3]. Becker and Appel, at the request of the Cordage Institute and the Federal Specification Board, investigated the color characteristics of manila rope fiber and in 1933 reported a quantitative visual method of evaluation [3, 4]. One result of their investigation was the establishment of the "Becker value" of manila rope, defined as 100 times the ratio of the reflectance of a suitably prepared sample of fiber to that of a standard magnesium oxide layer for monochromatic light of approximately 500 $\mathrm{m} \mu$. Fiber and standard were equally illuminated at $45^{\circ}$ with CIE (Commission Internationale de l'Éclairage) standard source $\mathrm{A}$ and viewed perpendicularly. Measurements were made with a Martens (visual) photometer with a Wratten filter No. 75 over the eyepiece.

Despite the lack of data on correlation of color with serviceability, measurements of Becker value continue to be made and appear to have facilitated the purchase of satisfactory manila cordage. With the passage of time, considerable confidence has been placed in the efficacy of Becker value measurements, and they will probably continue to be used in cordage specifications for some time.

Since the method was first described, Becker value has been determined by means of a reflectometer utilizing a Martens (visual) photometer. The procedure requires four pairs of observations, or settings, with the visual photometer, averaged to obtain one determination. As with all visual photometers, the results are dependent on the skill and experience of

\footnotetext{
1 More recent data have not been released.

More recent data have not been released.
2 Figures in brackets indicate the literature references at the end of this paper.
}

the observer. Furthermore, the Martens photometer scale is graduated in degrees so that Becker values cannot be obtained directly from readings of the photometer. A precise direct-reading photometer would be more desirable. Thus there arose the desire to replace the visual apparatus for determining Becker value with photoelectric equipment. Therefore, a photoelectric reflectometer ${ }^{3}$ was adapted to meet the requirements for Becker value measurement.

\section{Instrumentation}

The optical arrangement of the photoelectric reflectometer chosen for use in determining Becker value is shown schematically in figure 1 . The filter system first tried consisted of (1) a Barnes luminosity filter [5] to correct the response of the photocell to

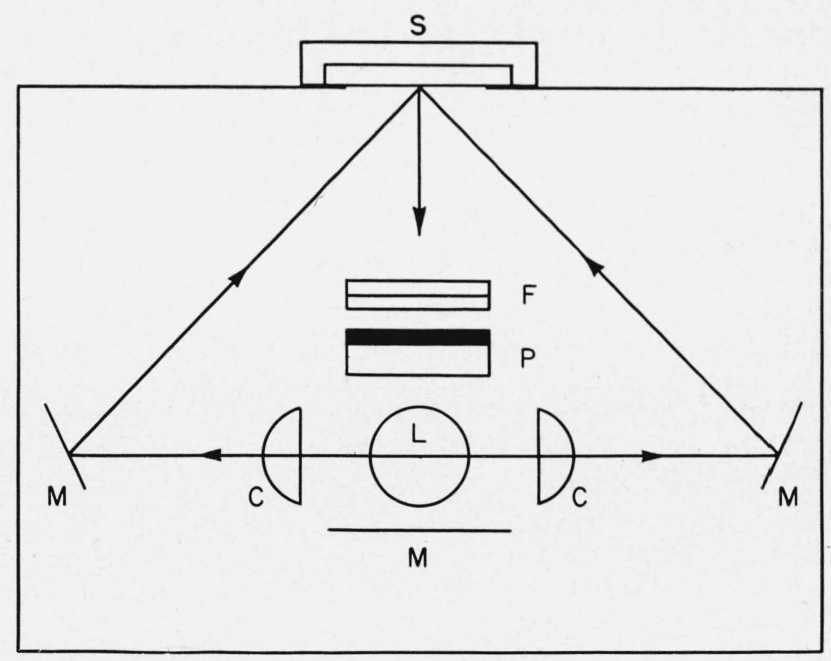

Figure 1. Schematic diagram of photoelectric reflectometer $\mathrm{S}$, Cell containing cut fiber; F, filters; $\mathrm{P}$, photocell; $\mathrm{M}$, mirrors; $\mathrm{C}$, condenser lenses; L, light source.

${ }^{3}$ This is the photometric unit with $45^{\circ} 0^{\circ}$ exposure head designed by Hunter [Gardner Laboratory, Bethesda, Md.]. 


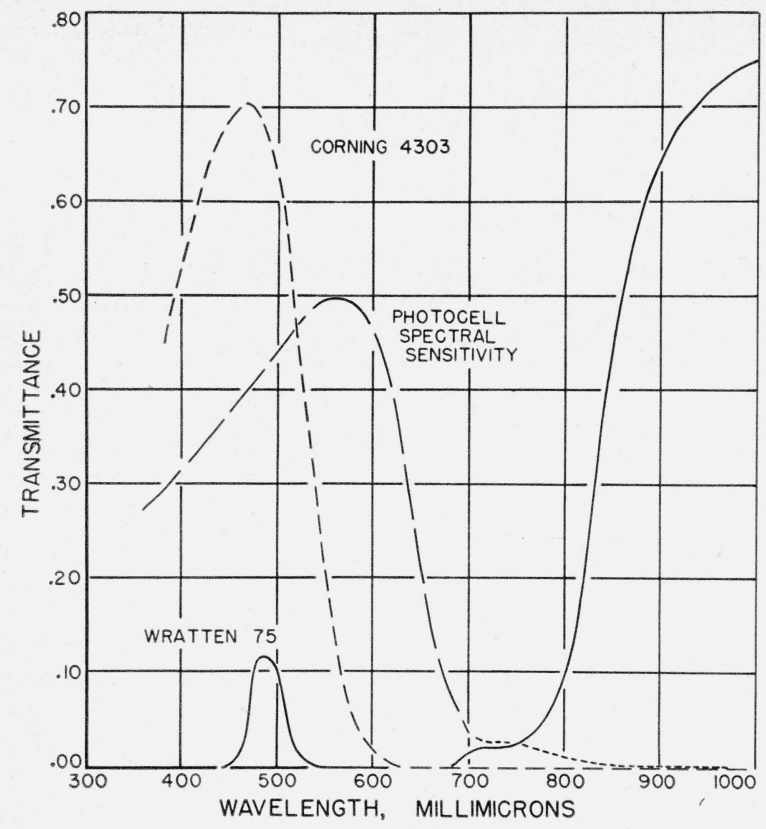

FIGURE 2. Spectral characteristics of filters and photocell used in the photoelectric reflectometer.

that of the CIE standard observer, and (2) a Wratten filter No. 75 to obtain essentially monochromatic light at $500 \mathrm{~m} \mu$, as required for the measurement of Becker value. Although nominally duplicating the spectral response of the visual method, this combination produced reflectometer readings considerably higher than those obtained visually. Substitution of a Hunter (bluer) luminosity filter [6] for the Barnes filter produced somewhat better agreement between the visual and photoelectric values. Investigation of the spectral characteristics of the sourcefilter-photocell combination revealed that infrared radiation was responsible for the high reflectance values obtained with the photoelectric reflectometer. Figure 2 shows the spectral response of a barrierlayer type photocell and the spectral transmittance of the Wratten filter 75. The Barnes and Hunter luminosity filters also transmitted some infrared radiation. To eliminate the infrared component and to obtain maximum sensitivity at $500 \mathrm{~m} \mu$, the luminosity filter was removed and a Corning glass 4303 was used to absorb the red and infrared radiation. This glass in combination with the Wratten filter 75 gave quite satisfactory results, as will be shown later.

The specimen holder ordinarily used with the Martens photometer provides too small an area of sample to permit the use of the entire illuminating beam of the photoelectric reflectometer. The specimen cell shown in figure 3 was constructed to permit large area illumination of the sample in the photoelectric reflectometer and still permit measurement in the visual instrument. The cell is constructed of methyl methacrylate. This material is easily worked
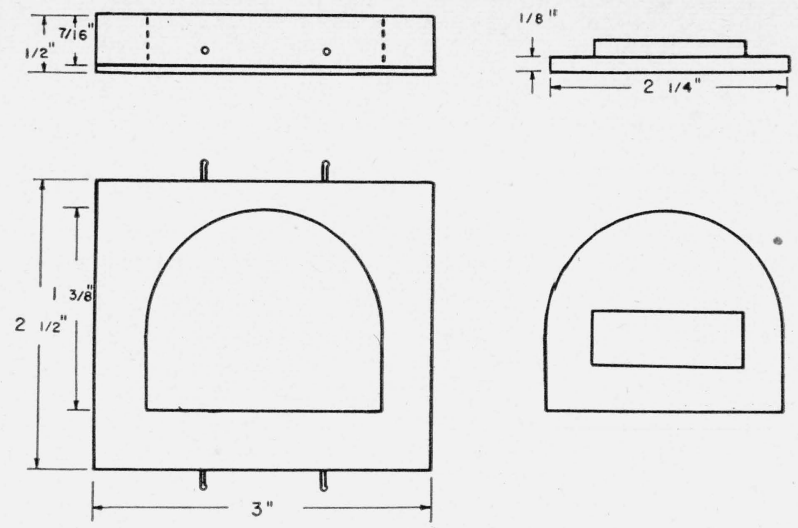

A

Figure 3. Plastic specimen cell used in photoelectric determinations.

A, Body of cell; B, back of cell. The back is held in place by the tension of rubber bands which are looped over the protruding studs in $\mathrm{A}$ and contact the back on the rectangular raised portion.

with ordinary laboratory tools, and the plastic provides a good, durable substitute for the "water white" cover glass, which often is not readily available. The plastic cover is softer than glass and will abrade with use, but replacement is easily accomplished. An electrostatic charge, induced by cleaning or filling the cell, can be removed with a gas flame or high relative humidity, as is done with conventional cells. Differential orientation of the fiber caused by a charged cell is readily detected photoelectrically by observing the instrument galvanometer while rotating the cell in its own plane. Specimen heating by the light source is much reduced with the photoelectric instrument as the light source draws about 20 watts as compared to 1,000 watts for the source in the visual instrument.

As with nearly all reflectometry, the primary reflectance standard for Becker value measurements is a freshly prepared layer of magnesium oxide. Working standards of porcelain enamel, however, are much easier to use. For greatest accuracy with visual or photoelectric reflectometers, a working standard should have spectral characteristics similar to those of the specimens being measured. Becker reported the spectral reflectance of fiber from 25 samples of 1-in. manila rope from 13 manufacturers [3] and the spectral reflectance of the Philippine Island Government standards [4]. The reflectance at $500 \mathrm{~m} \mu$ ranged from 20 to 60 percent. The spectral reflectances increased nearly linearly from 450 to $550 \mathrm{~m} \mu$ at the rate of approximately 0.15 percent per millimicron. A pale-yellow enamel working standard with a factor of 55.0, as related to 100 for $\mathrm{MgO}$, was used in most of this work. 


\section{Observations and Results}

Becker values were determined on several dozen samples of rope that had been submitted for test for conformance with the Federal specification [2]. The rope was prepared for test as described in the standard procedure, except that a rotary knife was used for cutting the fiber into the short lengths required. The knife was driven slowly, and no detectable scorching of the fiber occurred. Reflectance measurements were made visually and photoelectrically without disturbing the contents of the cells. In figure 4 the values obtained visually are plotted against those obtained photoelectrically. The relationship between the two sets of values is practically linear. Consequently, a straight line was fitted (broken line in fig. 4), using the method of least squares, and considering the precision of the photoelectric values as appreciably better than that of the Martens values. The equation for this line is

$$
y=1.21+0.97 x,
$$

where $x$ is the photoelectric value and $y$ the Martens value.

Statistical analysis of the data shows that the departure from a zero-intercept unit-slope relation is not attributable entirely to random fluctuation. From a practical viewpoint, however, these departures are unimportant. The minimum Becker values permitted by the Federal specification [2] are 40 for rope over $2 \mathrm{in}$. in circumference, and 43 for rope $2 \mathrm{in}$. in circumference and under. In the Becker value range 35 to 55 , the range of practical importance, the greatest discrepancy between the two methods is only 0.3 .

A statistical analysis has been made of 25 determinations of Becker value by one operator using one Martens photometer. From this analysis the conclusion was drawn that a single determination of Becker value by the visual method is unlikely to be in error by more than one unit. Comparison of data from different laboratories [7], however, indicates that as many as four determinations may be necessary for this precision. Observers of unequal experience show considerable variation of Becker value on the same specimen, and even experienced observers show a range of about 1.5 for 25 observations on the same sample.

Photoelectric determinations, on the other hand, are not influenced by the operator. It is estimated that instrument variations amount to as much as a few tenths of unit of Becker value.

In conclusion, it may be stated that the photoelectric method is considerably more precise than the visual method and that the two methods show a

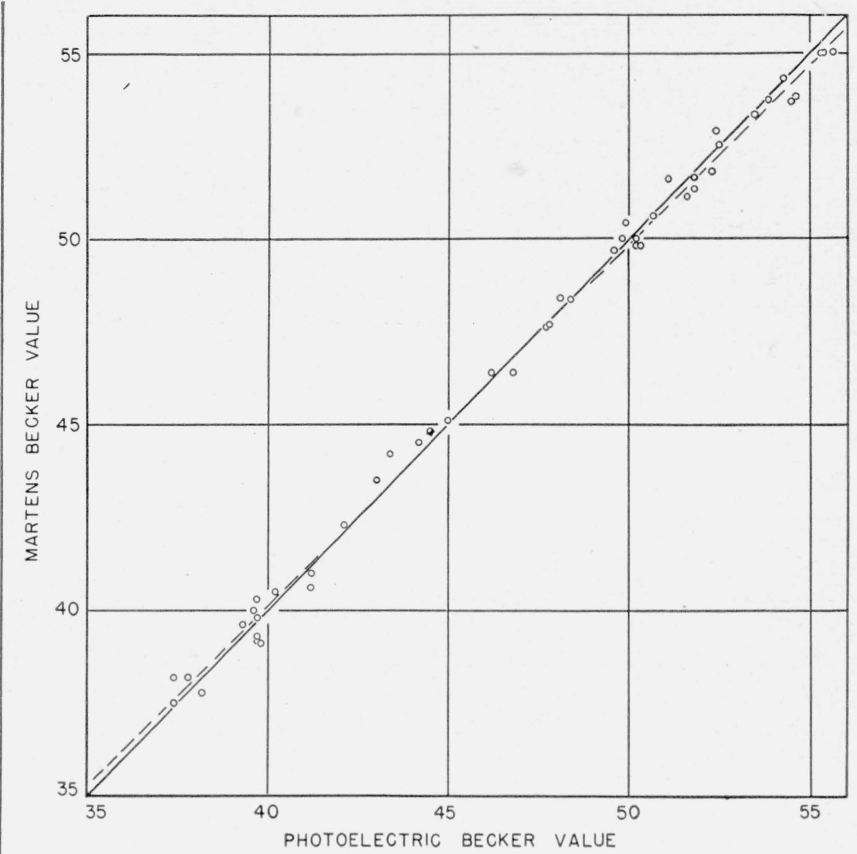

Figure 4. Photoelectric Becker values plotted against visual values.

Broken line represents the least-square line.

systematic variation of not more than 0.3 unit over the extreme range of interest.

The authors acknowledge the assistance of John Mandel in analyzing the data.

\section{References}

[1] Mathews' textile fibers, 5th ed., edited by Herbert Mauersberger (John Wiley \& Sons, New York, N. Y., 1947).

[2] Federal Standard stock catalog, sec. IV, part 5, Federal Specification T-R-601a for Rope; Manila, (Nov. 26, 1935) and Amendment 2 (Dec. 10, 1943).

[3] G. Becker and W. D. Appel, Evaluation of manila-rope fiber for color, BS J. Research 11, 811 (1933) RP627.

[4] G. Becker, Spectral reflectance of the Philippine Island Government Standards for abaca fiber, BS J. Research 11, 823 (1933) RP628.

[5] B. T. Barnes, A four-filter photoelectric colorimeter, J. Opt. Soc. Am. 29, 448 (1939).

[6] R. S. Hunter, Photoelectric tristimulus colorimetry with three filters, NBS Circular 429 (1942).

[7] G. Becker, Measurement of reflectance for interlaboratory comparison, letter report to the Cordage Institute (1940).

Washington, July 10, 1953. 